\title{
Effects of rat bone marrow-derived mesenchymal stem cells on breast cancer cells with differing hormone receptor status
}

\author{
YING WANG ${ }^{1}$, SHAN SHAO $^{2}$, MINNA LUO $^{2}$, SHANGKE HUANG $^{2}$, LU FENG $^{2}$, \\ NA YUAN ${ }^{2}$, FANG WU $^{2}$, CHENGXUE DANG $^{1}$ and XINHAN ZHAO ${ }^{2}$ \\ Departments of ${ }^{1}$ Surgical Oncology and ${ }^{2}$ Oncology, The First Hospital Affiliated to The School of Medicine, \\ Xi'an Jiaotong University, Xi'an, Shaanxi 710061, P.R. China
}

Received January 18, 2016; Accepted June 23, 2017

DOI: $10.3892 / \mathrm{ol} .2017 .7130$

\begin{abstract}
Breast cancer is a heterogeneous disease that can be classified into several molecular intrinsic subtypes according to hormone markers, including estrogen receptor, progesterone receptor and human epidermal growth factor receptor-2. Breast cancer cases with different hormone status vary with respect to patient morbidity, metastasis organotropism and disease progression. It is well known that the most preferential relapse site of breast cancer is in the bone, but the metastatic incidence is markedly higher in hormone receptor-positive cancer compared with that in hormone receptor-negative cancers. Bone marrow-derived mesenchymal stem cells (BMSCs) perform important roles at the site of metastasis; however, the effects in different tumors or tumor subtypes are controversial. The present study aimed to explore the various effects of BMSCs on the biological characteristics of different hormone receptor statuses. BMSCs were obtained from female rats and characterized by cell lineage-specific antigens. The MCF-7 and MDA-MB-231 breast cancer cell lines, which are hormone receptor-positive and -negative, respectively, were employed in the present study. The cancer cells were co-cultured with BMSCs, and changes in the biological characteristic of cell growth, apoptosis, migration and epithelial-mesenchymal transition (EMT) were assessed. BMSCs exhibited chemotactic attraction to MCF-7, promoted the proliferation of MCF-7 cells and reduced MCF-7 cell apoptosis. By contrast, BMSCs exerted no marked effects on these behaviors of MDA-MB-231 cells. However, following co-culture with BMSCs, the migratory ability was enhanced in the two cell lines. Furthermore, the expression of epithelial
\end{abstract}

Correspondence to: Professor Xinhan Zhao, Department of Oncology, The First Hospital Affiliated to The School of Medicine, Xi'an Jiaotong University, 277 West Yanta Road, Xi'an, Shaanxi 710061, P.R. China

E-mail: zhaoxinhanprof@163.com

Key words: breast cancer, hormone receptor, bone marrow-derived mesenchymal stem cells, biological behaviors, epithelial-mesenchymal transition markers (epithelial-cadherin and occludin) was decreased, and mesenchymal marker vimentin was markedly increased in the two cell lines. Notably, the migratory ability of MDA-MB-231 cells was attenuated compared with that of MCF-7 cells. The results from the present study indicated that BMSCs may favor receptor-positive cancer cell proliferation in bone and promote enhanced invasiveness of receptor-negative compared with receptor-positive cancer cells.

\section{Introduction}

Bone is a common distant relapse site for the majority of tumor types, including breast cancer; however, the incidence of bone metastasis varies between tumor types, as well as between breast cancer subtypes (1). According to the status of hormone receptors, including estrogen receptor (ER), progesterone receptor (PR) and human epidermal growth factor receptor-2 (HER2), or their gene expression profile, breast cancer cases can be classified into four major intrinsic biological subtypes (2). The characteristics and clinical appearance of various subtypes, including pathological grade $(3,4)$, risk factors (5), prognosis (6) and metastasis organotropism $(7,8)$, are all distinct. At present, personalized medicine is based on evidence that tumors are heterogeneous and different subtypes behave differently $(9,10)$. Therefore, increased attention must be directed to specific hormone or other marker distinctions.

The most common site of metastasis in breast cancer cases is the bone; however, the incidence of metastasis is distinct for each subtype of breast cancer $(8,11)$. The incidence of bone metastasis is highest in hormone receptor-positive cancer cases $(\sim 47.0 \%)$, with a lower incidence in hormone receptor-negative cancer cases ( 28.6\%) (11). Bone metastasis can diminish the possibility of curing the disease (12), and is associated with disseminated tumor cells (DTCs), which are independent prognostic factors and may cause relapse in distant organs (13). Furthermore, the emergence of DTCs in bone has been reported to be promoted by bone marrow-derived mesenchymal stem cells (BMSCs) (14). Tumor cells that detach from the primary tumor may enter into the circulation, settle in the bone marrow and interact with BMSCs (14). BMSCs can also migrate to the primary tumor location (15) and differentiate into fibroblasts or other stromal cells (16). These findings indicated that 
interactions between breast cancer cells and different forms of BMSCs occur continuously during tumor progression.

As aforementioned, BMSCs can interact with tumor cells and affect certain biological characteristics, including proliferation, migration, invasion and metastasis, in the tumor microenvironment of the primary tumor and of the bone metastatic lesion. However, there is no consensus regarding the effects MSCs exert on different tumors. MSCs have been reported to favor tumor growth in colorectal and lung cancer $(17,18)$, and to inhibit growth in lymphoma and Kaposi sarcoma $(19,20)$. To the best of our knowledge, the effects of BMSCs on breast cancer have not been elucidated, and there are currently few studies on the effects of BMSCs on different subtypes. Albarenque et al (21) and Karnoub et al (22) determined that MSCs enhanced the ability of invasion and metastasis of the MDA-MB-231 (basal-like) cell line. Corcoran et al (14) demonstrated that BMSCs facilitate the entrance of MDA-MB-231, MCF-7 and T47D cells (all hormone receptor-positive) to the bone marrow, and the metastatic abilities of these cells were promoted to various levels in these three cell lines.

The findings mentioned above indicate that the effects of BMSCs on tumor cells are dependent on the intrinsic biological characteristics of tumors. As for breast cancer, BMSCs may perform dissimilar roles in the heterogeneous molecular subtypes.

In the present study, co-culture models were established in vitro by culturing BMSCs and two breast cancer cell lines with a distinct hormone receptors status. The present study aimed to compare the effects exerted by BMSCs on the viability, chemotactic movement and migratory ability of each breast cancer cell line, and to explore whether the breast cancer cells undergo the epithelial-mesenchymal transition (EMT), which is a crucial event in tumor development (23).

\section{Materials and methods}

Culture of rat BMSCs. Rat BMSCs were obtained from the thighbone of female Sprague Dawley ${ }^{\circledR}$ rats. The rats were purchased from Silaike Laboratory Animal Co., Ltd., Shanghai, China, at 4 weeks of age, weighing 100 g. The animals were fed with standard fodder provided by Beijing Huafukang Biotechnology Co., Ltd. (Beijing, China) and housed in independent ventilated cages, ventilated with fresh air 8-12 times every hour, and at a temperature of $\sim 22^{\circ} \mathrm{C}$ with a humidity of $40-70 \%$, in a $12 / 12 \mathrm{~h}$ lightldark cycle. One rat was used for each BMSCs acquisition, from a total number of five rats used in the present study. BMSCs were cultured in a plastic culture dish at $37^{\circ} \mathrm{C}$ in an atmosphere of $5 \% \mathrm{CO}_{2}$. In the primary culture (passage 0 ), the medium (Dulbecco's modified Eagle's medium/Nutrient Mixture F12 (DMEM/F12) supplemented with $10 \%$ fetal bovine serum (FBS) and $1 \%$ penicillin-streptomycin) was changed every $8 \mathrm{~h}$ for a total of $72 \mathrm{~h}$ to eliminate the non-adherent cells, including hematopoietic cell lineages. The adherent cells were then cultured, with the medium replaced every 2 days until the cells obtained $90 \%$ confluency. Subsequently, the cells were incubated in $0.5 \mathrm{ml}$ of $0.25 \%$ trypsin/ $1 \mathrm{mM}$ EDTA for 2 min at room temperature. The culture media DMEM/F12, FBS, penicillin-streptomycin, and trypsin were all purchased from Gibco; Thermo Fisher Scientific, Inc. (Waltham, MA, USA). The harvested cells were seeded on a new culture dish and the remaining cells, including fibroblasts, were discarded. Isolation and purification of BMSCs was accomplished according to the protocol reported in the mice BMSC culture performed by Soleimani and Nadri (24). BMSCs at passage 3 or 4 were used for subsequent experiments. The study was approved by the Ethics Committee of Xi'an Jiaotong University (Jiaotong, China). All procedures were performed in accordance with the Principles of Laboratory Animal Care (National Institutes of Health, Bethesda, MD, USA) and the guidelines of the Laboratory Animal Care Committee of Xi'an Jiaotong University.

Identification of BMSCs by flow cytometry. DMSCs at a density of $5 \times 10^{5}$ from passage three were harvested by centrifugation at $250 \mathrm{x}$ g for $10 \mathrm{~min}$ at $4^{\circ} \mathrm{C}$, then washed in pre-cooled PBS and incubated for 30 min with $5 \%$ bovine serum albumin (Sigma-Aldrich; Merck KGaA, Darmstadt, Germany) at $4^{\circ} \mathrm{C}$. Cells were then incubated for $20 \mathrm{~min}$ with $100 \mu \mathrm{l}$ fluorescein-conjugated monoclonal primary antibodies: Phycoerythrin (PE) -conjugated anti-rat CD90 (cat. no. 205903; dilution, 1:1,000), fluorescein isothiocyanate (FITC)-conjugated anti-rat CD29 (cat. no. 102205; dilution, 1:100), PE-conjugated anti-rat CD34 (cat. no. Sc-7324PE; dilution, 1:100) and FITC-conjugated anti-rat CD45 (cat. no. 202205; dilution, 1:200). Anti-rat CD90, CD29 and CD45 antibodies were bought from BioLegend, Inc. (San Diego, CA, USA). Anti-rat CD34 antibody was purchased from Santa Cruz Biotechnology, Inc. Dallas, TX USA). Then, the cells were washed with PBS $\left(250 \mathrm{~g} \times \mathrm{g}\right.$ for $10 \mathrm{~min}$ at $4^{\circ} \mathrm{C}$ and resuspended the cells in $500 \mu \mathrm{l}$ PBS for each group. The immunofluorescence analysis was conducted with BD flow cytometer and the image was depicted and data proceeded using BD CellQuest (BD Biosciences, Franklin Lakes, NJ, USA). Antibody selection was performed according to Dominici's criteria (25).

Culture of human breast cancer cell lines. The human breast cancer cell lines (MCF-7 and MDA-MB-231) used in the present study were purchased from the Cell Bank of Type Culture Collection of the Chinese Academy of Sciences (Shanghai, China). MCF-7 is an ER- and PR-positive cell line, while MDA-MB-231 is an ER- and PR-negative cell line. The human breast cancer cells were cultured in DMEM/F12 supplemented with $10 \%$ FBS and $1 \%$ penicillin-streptomycin, which was the same as the BMSCs. All cells were grown at $37^{\circ} \mathrm{C}$ in an atmosphere of $5 \% \mathrm{CO}_{2}$.

Chemotaxis assay. An equal number of $5 \times 10^{4}$ BMSCs were seeded in three experimental wells of a 24 -well plate, while the control wells contained an equivalent volume of culture

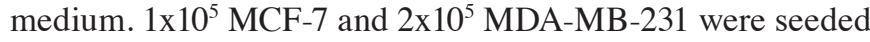
respectively in $8 \mu \mathrm{m}$ Transwell chambers (EMD Millipore, Billerica, MA, USA) inserted in a 24-well plate. The cells were all incubated in DMEM/F12 supplemented with $10 \%$ FBS and $1 \%$ penicillin-streptomycin for $24 \mathrm{~h}$, then the non-migrated cells were removed from the upper chamber with a cotton swab. The cells that had migrated through the membrane were fixed with $4 \%$ paraformaldehyde for $30 \mathrm{~min}$ 
at room temperature then washed with PBS and stained with $0.01 \%$ crystal violet solution for $20 \mathrm{~min}$. Images of the migrated purple cells were captured with a Leica inverted microscope (Leica Microsystems, Inc., Buffalo Grove, IL, USA). The numbers of cells that migrated were determined from six random high-power fields visualized at x100 magnification. The stainer in the migrated cells was dissolved in $500 \mu 133 \%$ acetic acid. The optical density (OD) values at $570 \mathrm{~nm}$ of the solution were recorded and the data were used for statistical analysis.

MTT assay. A number of $800 \mathrm{MCF}-7$ and $1500 \mathrm{MDA}-\mathrm{MB}-231$ were seeded into the wells of four 96-well plates, in which 18 wells ( 6 wells for each cell line) were experimental and 18 were control. The culture media of the experimental groups were replaced every $24 \mathrm{~h}$ with the supernatant in which BMSCs had been cultured for $6 \mathrm{~h}$. The media of the control groups was replaced with the supernatant in which the cancer cells had been cultured for $6 \mathrm{~h}$. The culture of each plate was terminated every $24 \mathrm{~h}$ by adding MTT in the culture wells. The purple formazan deposited in viable cells was then dissolved in DMSO and the OD value was measured at $570 \mathrm{~nm}$.

Analysis of apoptosis by flow cytometry. Cancer cells at a density of $1 \times 10^{5}$ cells $/ 1 \mathrm{ml}$ of each cell line in each experiment group were plated in six $0.4 \mu \mathrm{m}$ Transwell chambers (EMD Millipore) in a 6-well plate. BMSCs were seeded in three repeated experimental wells and $1 \mathrm{ml}$ culture medium was added to the remaining three wells as a control. Cell passaging was conducted as necessary during the following 7 days of co-culture. Subsequently, $5 \times 10^{5}$ cancer cells were harvested by trypsin digestion and centrifuged at $250 \mathrm{x}$ g for $5 \mathrm{~min}$ at $4^{\circ} \mathrm{C}$. Following this, the cancer cells were incubated with $5 \mu \mathrm{l}$ Annexin V-FITC and $10 \mu \mathrm{l}$ propidium iodide in $500 \mu \mathrm{l}$ binding buffer for 20 min (Annexin V-FITC/PI Apoptosis Detection kit was purchased from Wanlei Biological Technology Co. Ltd., Shenyang, Liangning, China). The apoptosis assay was conducted by $\mathrm{BD}$ flow cytometer and the image was depicted and data processed by BD CellQuest Pro (version 3.1; BD Biosciences, Franklin Lakes, NJ, USA). The proportion of apoptotic cells in the control groups was set at 1 , and the proportion in the co-cultured groups were counted as a ratio of the control groups.

Cell migration assay. Cancer cells employed in the migration assay were harvested from the experimental and control groups in the $0.4 \mu \mathrm{m}$ Transwell co-culture models, as described for the apoptosis assay. Cancer cells were then suspended in $8 \mu \mathrm{m}$ Transwell chambers (EMD Millipore) laid on 6-well plates. Culture media with $20 \%$ FBS was placed in the lower wells. Following incubation for $24 \mathrm{~h}$, the non-migrated cells were removed from the upper chamber with a cotton swab. The cells that had migrated through the membrane were fixed with $4 \%$ paraformaldehyde for $30 \mathrm{~min}$ at room temperature, washed with PBS and stained with $0.01 \%$ crystal violet solution for $20 \mathrm{~min}$ at room temperature. Images were captured and the optical density (OD) values at $570 \mathrm{~nm}$ were recorded, aforementioned for the chemotaxis assay.
Western blot analysis and antibodies. The tumor cells were harvested subsequent to 7 days of co-culture with BMSCs. Total protein was extracted using the Whole Cell Lysis Assay kit (Shaanxi Pioneer Biotech Co., Ltd., Xi'an, China) according to the manufacturer's protocol. Equal amounts of protein $(40 \mu \mathrm{g})$ were separated via $10 \%$ SDS-PAGE and then transferred to a polyvinylidene difluoride membrane (Roche Diagnostics, Basel, Switzerland). The immunoblots were incubated in $5 \%(\mathrm{w} / \mathrm{v})$ skim milk powder dissolved in TBST (10 mM Tris- $\mathrm{HCl}, \mathrm{pH} 8.0,150 \mathrm{mM} \mathrm{NaCl}$ and $0.05 \%$ Tween-20) for $2 \mathrm{~h}$ at room temperature. The target blots were then probed with primary antibodies against, mouse anti-human E-cadherin (cat. no. 5296; dilution, 1:1,000), mouse anti-human vimentin (cat. no. 5296; dilution, 1:1,000), purchased from Cell Signaling Technology, Inc., Danvers, MA, USA. The mouse anti-human occludin (cat. no. sc-133256; dilution, 1:1,000), mouse anti-human $\beta$-actin (cat. no. sc-58673; 1:1,000), purchased from Santa Cruz Biotechnology, Inc., Dallas, TX, USA. All primary antibodies were incubated with the PVDF membrane at $4^{\circ} \mathrm{C}$ overnight. Membranes were then labeled with the appropriate secondary antibody, horseradish peroxidase conjugated- anti-mouse IgG antibody (cat. no. 7076; dilution, 1:10,000) purchased from Cell Signaling Technology, Inc., and incubated at room temperature for $2 \mathrm{~h}$. $\beta$-actin was used as the internal control. The proteins were detected using a Thermo Chemical luminescence immunity analyzer (Thermo Fisher Scientific, Inc.), and the signals were quantified using Image-J2X software (version 2.1.4.7; Wayne Rasband; National Institutes of Health).

Statistical analysis. All data are presented as the mean \pm standard deviation. Data were analyzed using the one sample or independent sample t-test as appropriate. Statistical analysis was performed using SPSS version 20 software (IBM Corp., Armonk, NY, USA), and $\mathrm{P}<0.05$ was considered to indicate a statistically significant difference. All experiments were repeated independently $\geq 3$ times.

\section{Results}

Isolation and characterization of BMSCs. BMSCs were isolated from the thighbone of female Sprague Dawley rats, weighing $\sim 100 \mathrm{~g}$. The initial adherent spindle-shaped cells surrounded by small round hematopoietic cells appeared on day 2 (Fig. 1Aa). Within 7 days, the spindle-shaped cells reached $80-90 \%$ confluency and the small round cells became less common (Fig. 1Ab-d). By strict control of the trypsinization time during the cell propagation and frequent medium change, stable unified spindle-shaped cells growing in a gyrate pattern were obtained (Fig. 1Ae and f).

BMSCs in passage 3 were characterized with flow cytometry by mesenchymal cell lineage-specific antigens CD90 and CD29 and hematopoietic cell lineage-specific antigens CD34 and CD45. CD29 and CD90 were expressed on the obtained cells whereas CD34 and CD45 were almost absent (Fig. 1B).

Chemotactic attraction of BMSCs to breast cancer cell lines. To investigate the chemotactic attraction of BMSCs to each breast cancer cell line, the cancer cells were incubated 
A

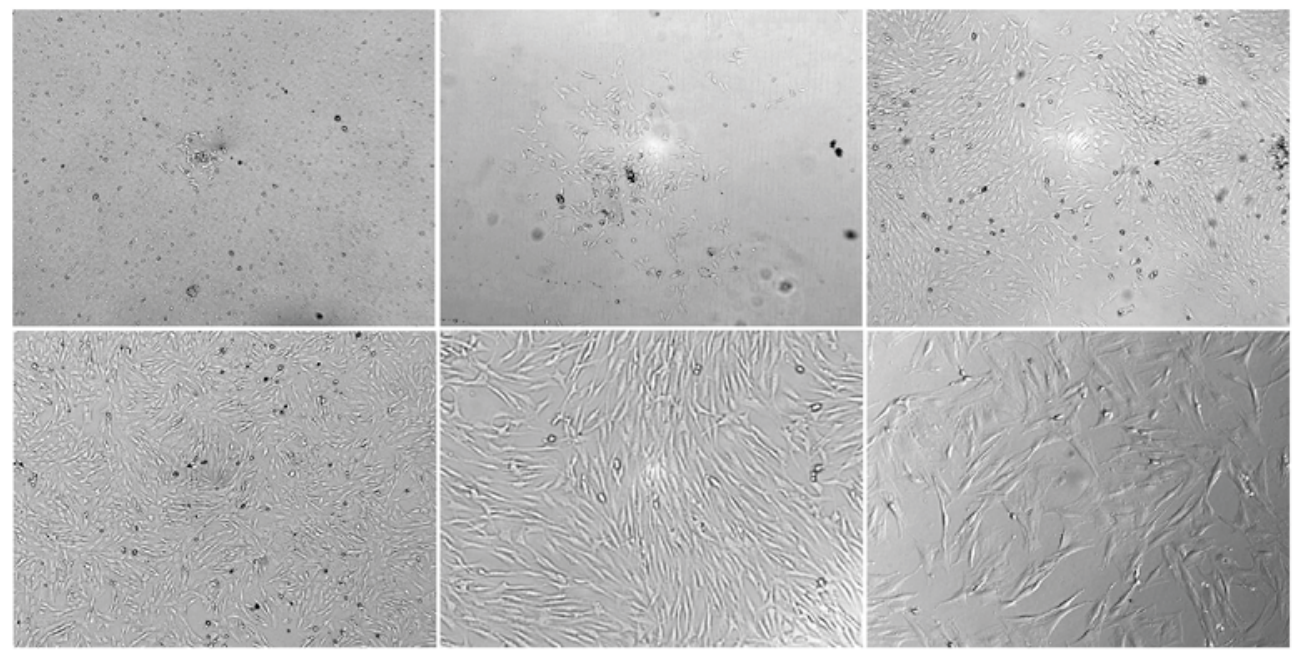

B
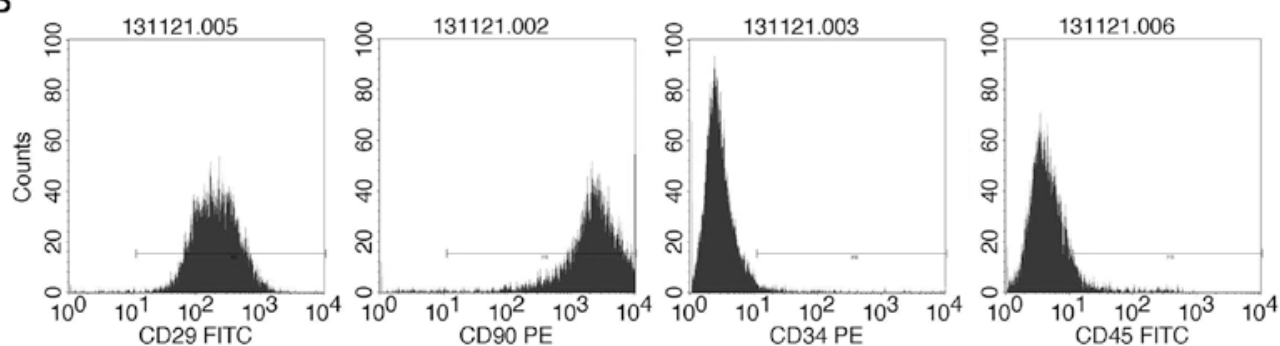

Figure 1. Isolation and identification of rat BMSCs. On the 2nd day of the primary culture, a small colony of BMSCs was observed in the culture dish (A upper left; magnification, $\mathrm{x} 40$ ). Isolated BMSCs of the primary culture on the (A upper middle; magnification, $\mathrm{x} 40$ ) 3rd, (A upper right; magnification, $\mathrm{x} 40$ ) 5th and (A lower left; magnification, $\mathrm{x} 40$ ) 6th day. The supernatant became clearer and the small round cells became rare in the field. The colony of BMSCs grew bigger and gradually became confluent. The morphology of BMSCs in passage 3 (A lower middle; magnification, x100 and A lower right; magnification, $\mathrm{x} 200$ ). BMSCs is spindle-shaped with smooth and keen edges and grew along the cell macroaxis. (B) Surface marker expression on the isolated cells. The proportion of expression of CD90, CD29, CD34 and CD45 was 99, 99.61, 2.02 and 7.79\%, respectively. CD, cluster of differentiation; BMSC, bone marrow-derived mesenchymal stem cell; FITC, fluorescein isothiocyanate; PE, phycoerythrin.

\section{A}

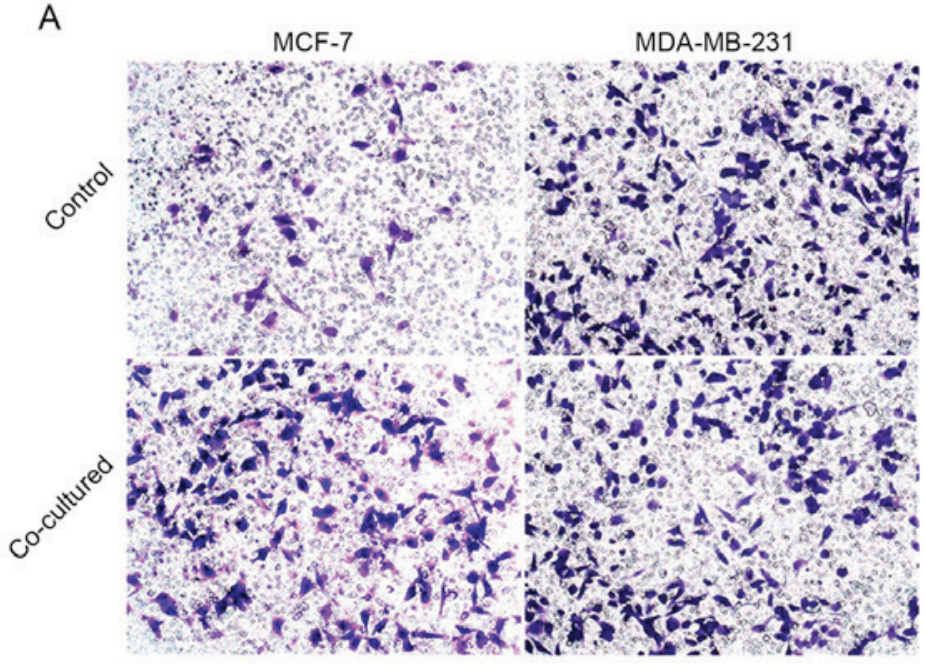

B
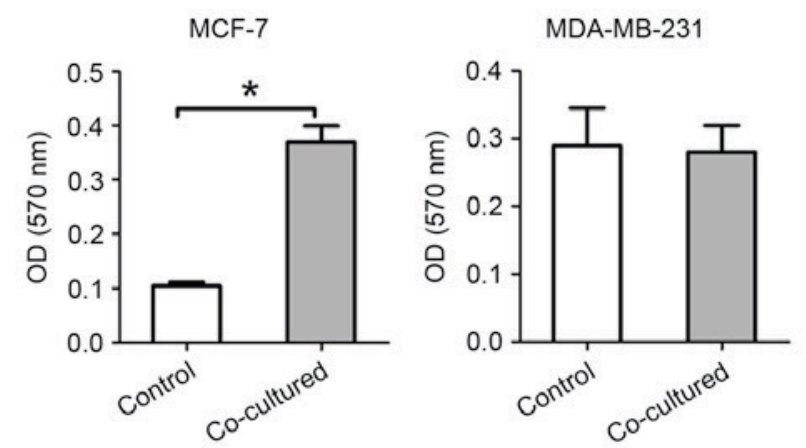

Figure 2. Chemotaxis of breast cancer cells to BMSCs. (A) In the $8 \mu \mathrm{m}$ Transwell chamber co-culture system with BMSCs, MCF-7 cells migrated chemotactically through the Transwell membrane more compared with that in the control group, while MDA-MB-231 migrated similarly in the two groups. Images were captured at magnification, x100. (B) The OD value of crystal violet solution dissolved in acetic acid recorded at $570 \mathrm{~nm}$. Data are presented as the mean \pm standard deviation. " $\mathrm{P}<0.05$. BMSC, bone marrow-derived mesenchymal stem cell.

with BMSCs in $8 \mu \mathrm{m}$ Transwell chambers. The number of migrated cells and the OD value of the stain solution in acetic acid were recorded. The results revealed that MCF-7 cells migrated further in the co-culture group, whereas the rate of MDA-MB-231 cell migration was similar between the two groups (Fig. 2). The OD values of the $33 \%$ acetic acid solution 

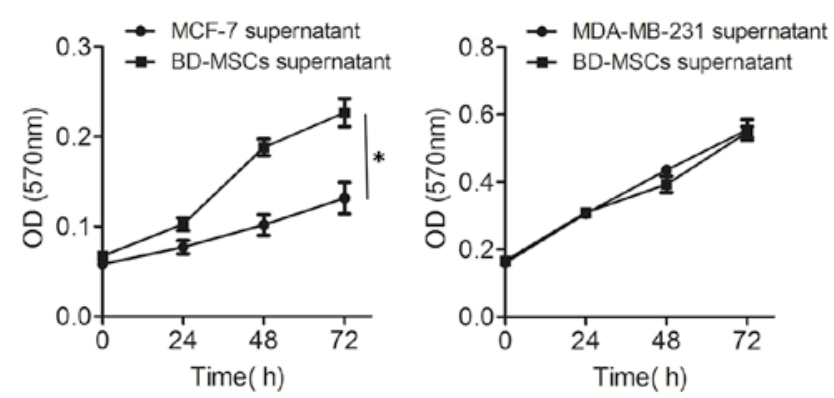

Figure 3. Proliferation of breast cancer cells was affected by BMSCs. Proliferation of MCF-7 was significantly promoted $\left({ }^{*} \mathrm{P}<0.05\right)$ in the co-culture system with BMSCs, but the growth of MDA-MB-231 was not significantly affected. Data are presented as the mean \pm standard deviation. BMSC, bone marrow-derived mesenchymal stem cell; OD, optical density.

of crystal violet (which stained the cancer cells of the experiment and control groups) were $0.105 \pm 0.007$ and $0.370 \pm 0.030$, $0.290 \pm 0.055$ and $0.281 \pm 0.039$, respectively.

Effect of BMSC supernatant on the proliferation of breast cancer cells. Supernatant that was mediated by BMSCs for $6 \mathrm{~h}$ was added to the breast cancer cell culture to assess the effect of BMSCs on the proliferation of cancer cells. Results from the MTT assay indicated that the BMSC supernatant could promote the proliferation and viability of MCF-7 cells, but had little effect on the proliferation of MDA-MB-231cells (Fig. 3).

Proportion of apoptotic breast cancer cells following co-culture with BMSCs. The proportions of apoptotic cells from each cell line following co-culture with BMSCs varied from one another. The proportion of apoptotic cells was reduced in MCF-7 cells, while no significant change was observed in MDA-MB-231 cells (Fig. 4) following co-culture. The proportions of apoptotic cells in the experimental and control groups were $16.0 \pm 3.01$ and $12.5 \pm 2.93 \%, 10.6 \pm 0.00$ and $11.7 \pm 0.73 \%$, respectively.

Migratory ability of breast cancer cells is promoted by BMSCs. The migratory ability of breast cancer cells harvested following 7 days of co-culture with BMSCs was detected in the $8 \mu \mathrm{m}$ Transwell chamber. Relative to the control, each experimental cell group exhibited an increased rate of migration (Fig. 5A and B). The results demonstrated that BMSCs promoted the migration of breast cancer cells independent of the hormone receptor status. Notably, the migration fold-change of MDA-MB-231 cells was higher than that of MCF-7 cells (Fig. 5C). The results indicated that the migratory ability changes level is hormone receptor status-dependent.

Breast cancer cells undergo EMT following co-culture with BMSCs. MCF-7 and MDA-MB-231 cells were co-cultured with BMSCs for 7 days, following which the total protein was extracted to determine the expression of certain EMT markers via western blot analysis. The results revealed that the two cancer cell lines underwent EMT. Expression of the epithelial markers E-cadherin and occludin was decreased,
A
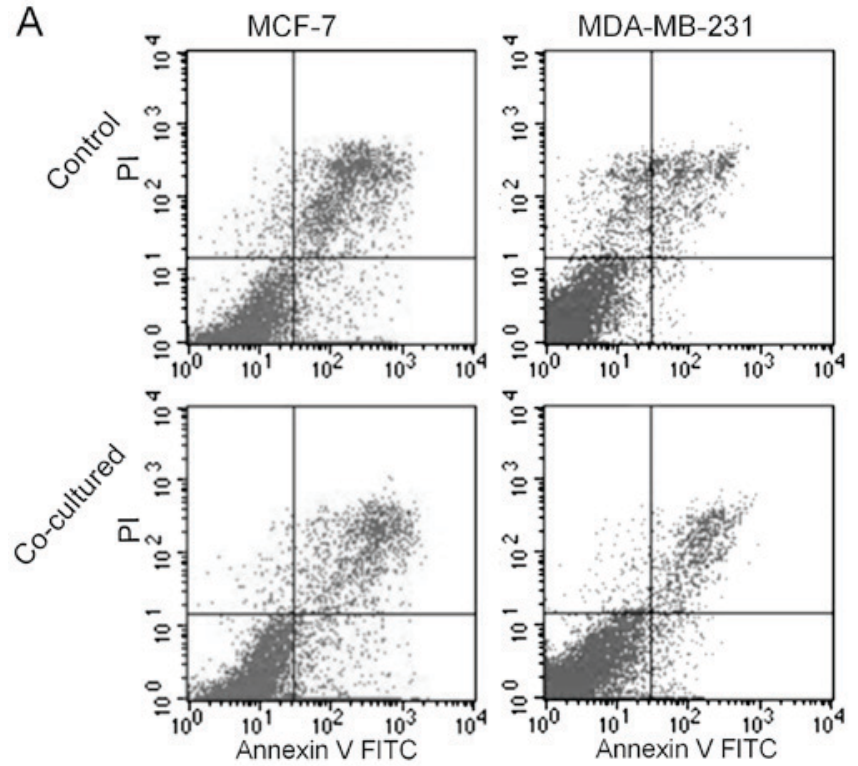

B

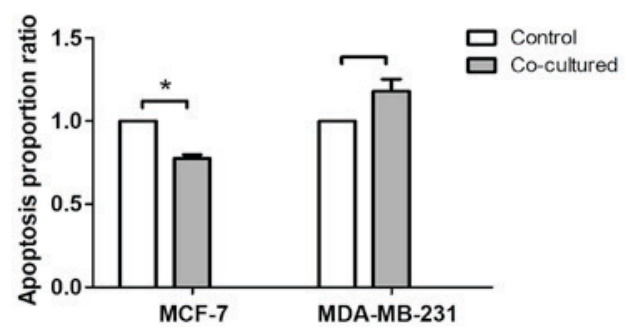

Figure 4. Proportion of apoptotic breast cancer cells was changed following co-culture with BMSCs. (A) The proportion of apoptotic MCF-7 cells in the co-cultured group was decreased, while there was no change in the proportion of apoptotic MDA-MB-231 cells. (B) The proportion of apoptotic cells in the control groups was set as 1 , and the proportion in the co-cultured groups is presented as a ratio. A significant difference was observed in MCF-7. Data are presented as the mean \pm standard deviation. ${ }^{*} \mathrm{P}<0.05$. BMSC, bone marrow-derived mesenchymal stem cell; FITC, fluorescein isothiocyanate; PI, propidium iodide.

and expression of the mesenchymal marker vimentin was increased in MCF-7 cells. E-cadherin and occludin expression were decreased in MDA-MB-231 cells (Fig. 6).

\section{Discussion}

The present data demonstrated that highly purified rat BMSCs can be obtained by changing the culture medium frequently in primary culture and diminishing the trypsinization time as well as the process in obtaining mouse BMSCs (24).

Results from the present study illustrated that the BMSCs had varied effects on different breast cancer cell lines in vitro, as expected. Taken together, the present data demonstrated that BMSCs had chemotactic attraction for MCF-7 and could promote the proliferation and reduce the apoptosis of MCF-7 cells. By contrast, BMSCs had no notable chemotactic attraction and no effect on the proliferation and apoptosis of MDA-MB-231 cells. Despite the differences in these aspects, the migratory abilities of the two cell lines were both enhanced following co-culture with BMSCs. The expression of epithelial markers was promoted and the expression of mesenchymal markers was inhibited. 


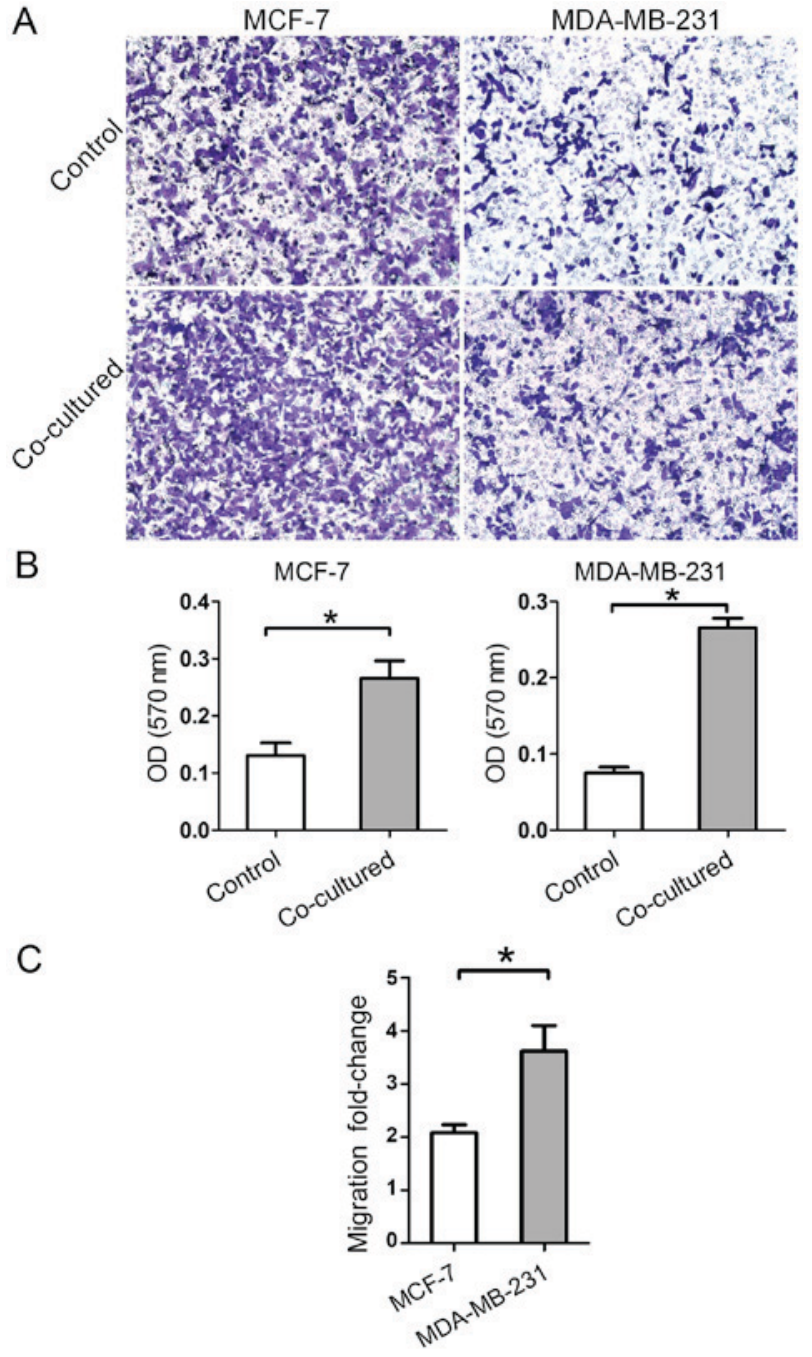

Figure 5. Migratory ability of breast cancer cells was promoted following co-culture with BMSCs. (A) An increased number of migrated cells was observed in the two cell lines at 1 week post-co-culture with BMSCs (magnification, x100). (B) The OD value of the cell stain crystal violet solution dissolved in acetic acid was recorded at $570 \mathrm{~nm}$. Migratory ability was significantly promoted in the two cell lines. (C) The ratios of the OD values in the co-culture groups to those in the control groups were compared. Migration fold-change was significantly higher in MDA-MB-231 cells as compared with in MCF-7 cells. Data are presented as the mean \pm standard deviation. ${ }^{*} \mathrm{P}<0.05$. BMSC, bone marrow-derived mesenchymal stem cell; OD, optical density.

Bone is the most common and first metastatic site for hormone receptor-positive cancer $(8,11)$, but for the basal-like (hormone receptor and HER2 negative) cancer, the first metastatic site is likely to be liver or brain $(7,11)$. Furthermore, hormone receptor-positive cases are reported to achieve fewer pathological complete responses and complete eradications of DTCs, which are independent predict risks of recurrence $(13,26,27)$ following neoadjuvant chemotherapy, compared with hormone receptor-negative cases (28). These studies indicate that hormone receptor-positive cancer cell be well sheltered in the bone against chemotherapy, and then contribute to relapse in other organs lately. Considering the effects of BMSCs on MCF-7 cells observed in our study and prior studies, it may be hypothesized that when the hormone receptor-positive cancer cells leave the primary site and enter the circulation, they may chemotactically locate to the

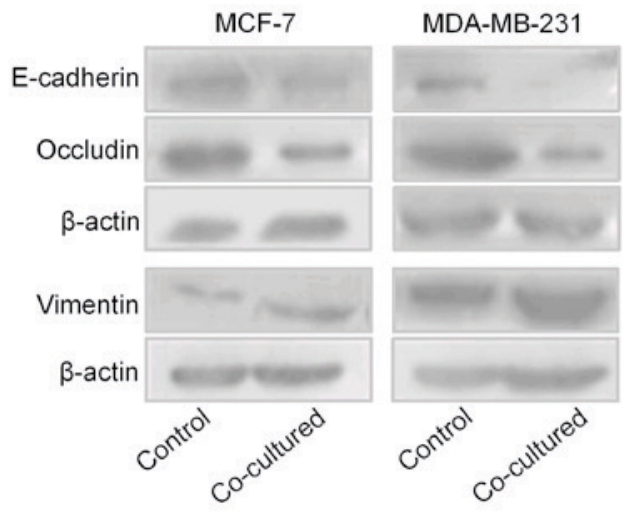

Figure 6. Breast cancer cells in the two cell lines underwent changes in expression of epithelial-mesenchymal-associated markers following co-culture with bone marrow-derived mesenchymal stem cells. E-cadherin and occludin expression was decreased and vimentin expression was increased in MCF-7 cells. E-cadherin and occludin expression was decreased in MDA-MB-231 cells.

bone and interact with the bone marrow. Proliferation may therefore then be promoted by BMSCs, thereby growing into overt metastatic lesions; which may also undergo EMT prior to migrating as DTCs, which may have fatal consequences. Therefore, additional attention must be paid to the prevention of bone metastasis in hormone receptor-positive cancer cases and their interactions with BMSCs in the bone.

MDA-MB-231 cells were not significantly affected by BMSCs with respect to cell proliferation, apoptosis and chemotaxis towards BMSCs. However, the migratory ability and EMT of MDA-MB-231 cells was promoted more intensively when compared with that of MCF-7 cells. Triple-negative breast cancer cases (TNBC; ER-negative, PR-negative and HER2-negative) were reported to rarely develop their first relapse in the bone but in the liver and brain $(11,29)$. However, the basal-like subtype is considered to be more aggressive and to have a poorer prognosis compared with the hormone receptor-positive subtypes (30). This indicates that triple-negative breast cancer may not metastasize in the bone prior to other organs, but once it metastasizes in the bone, the tumor cells may interact with BMSCs and undergo EMT and obtain a more invasive profile.

Notably, DTCs in the bone marrow may appear several years prior to the occurrence of bone metastasis (31), and be closely associated with a poor prognosis (32). Taken together, the results from this and previous studies indicated that once triple-negative breast cancer cells inhabit the bone marrow, they may drift into the circulation prior to the appearance of overt bone metastasis. Therefore, we suggest that the early diagnoses and treatments of bone metastasis of hormone receptor-negative cancer subtypes are crucial.

In conclusion, BMSCs have various effects on the proliferation, apoptosis and chemotactic movement of the breast cancer MCF-7 and MDA-MB-231 cell lines, which are hormone receptor-positive and -negative, respectively. However, the migratory ability and EMT of these cells are consistently promoted but at different levels. The limitation of our study was that there were no other breast cancer molecular markers included particularly HER2-enriched subtypes. The presence of HER2-enriched DTCs in patients with early breast cancer 
was also reported to be associated with a higher risk of relapse compared with that in hormone receptor-positive cancer cases (33). Therefore, more effects of BMSCs on multiple elaborate breast cancer subtypes should be observed and comparisons made, in an attempt to identify the underlying mechanisms. This may provide evidence to assist in improving the availability of personalized medicine in breast cancer.

\section{References}

1. Savci-Heijink CD, Halfwerk H, Hooijer GK, Horlings HM, Wesseling $\mathrm{J}$ and van de Vijver MJ: Retrospective analysis of metastatic behaviour of breast cancer subtypes. Breast Cancer Res Treat 150: 547-557, 2015

2. Goldhirsch A, Winer EP, Coates AS, Gelber RD, Piccart-Gebhart M, Thurlimann B and Senn HJ; Panel members: Personalizing the treatment of women with early breast cancer: Highlights of the St Gallen international expert consensus on the primary therapy of early breast cancer 2013. Ann Oncol 24: 2206-2223, 2013.

3. Yang XR, Sherman ME, Rimm DL, Lissowska J, Brinton LA, Peplonska B, Hewitt SM, Anderson WF, Szeszenia-Dabrowska N, Bardin-Mikolajczak A, et al: Differences in risk factors for breast cancer molecular subtypes in a population-based study. Cancer Epidemiol Biomarkers Prev 16: 439-443, 2007.

4. Spitale A, Mazzola P, Soldini D, Mazzucchelli L and Bordoni A: Breast cancer classification according to immunohistochemical markers: Clinicopathologic features and short-term survival analysis in a population-based study from the South of Switzerland. Ann Oncol 20: 628-635, 2009.

5. Tamimi RM, Colditz GA, Hazra A, Baer HJ, Hankinson SE, Rosner B, Marotti J, Connolly JL, Schnitt SJ and Collins LC: Traditional breast cancer risk factors in relation to molecular subtypes of breast cancer. Breast Cancer Res Treat 131: 159-167, 2012.

6. Wirapati P, Sotiriou C, Kunkel S, Farmer P, Pradervand S, Haibe-Kains B, Desmedt C, Ignatiadis M, Sengstag T, Schutz F, et al: Meta-analysis of gene expression profiles in breast cancer: Toward a unified understanding of breast cancer subtyping and prognosis signatures. Breast Cancer Res 10: R65, 2008.

7. Kennecke H, Yerushalmi R, Woods R, Cheang MC, Voduc D, Speers CH, Nielsen TO and Gelmon K: Metastatic behavior of breast cancer subtypes. J Clin Oncol 28: 3271-3277, 2010.

8. Smid M, Wang Y, Zhang Y, Sieuwerts AM, Yu J, Klijn JG, Foekens JA and Martens JW: Subtypes of breast cancer show preferential site of relapse. Cancer Res 68: 3108-3114, 2008.

9. Andre F, Mardis E, Salm M, Soria JC, Siu LL and Swanton C: Prioritizing targets for precision cancer medicine. Ann Oncol 25: 2295-2303, 2014.

10. Parker JS and Perou CM: Tumor heterogeneity: Focus on the leaves, the trees, or the forest?. Cancer Cell 28: 149-150, 2015.

11. Sihto H, Lundin J, Lundin M, Lehtimaki T, Ristimaki A, Holli K, Sailas L, Kataja V, Turpeenniemi-Hujanen T, Isola J, et al: Breast cancer biological subtypes and protein expression predict for the preferential distant metastasis sites: A nationwide cohort study. Breast Cancer Res 13: R87, 2011.

12. Weilbaecher KN, Guise TA and McCauley LK: Cancer to bone: A fatal attraction. Nat Rev Cancer 11: 411-425, 2011.

13. Janni W, Vogl FD, Wiedswang G, Synnestvedt M, Fehm T, Jückstock J, Borgen E, Rack B, Braun S, Sommer H, et al: Persistence of disseminated tumor cells in the bone marrow of breast cancer patients predicts increased risk for relapse--a European pooled analysis. Clin Cancer Res 17: 2967-2976, 2011.

14. Corcoran KE, Trzaska KA, Fernandes H, Bryan M, Taborga M Srinivas V, Packman K, Patel PS and Rameshwar P: Mesenchymal stem cells in early entry of breast cancer into bone marrow. PLoS One 3: e2563, 2008

15. Spaeth E, Klopp A, Dembinski J, Andreeff M and Marini F: Inflammation and tumor microenvironments: Defining the migratory itinerary of mesenchymal stem cells. Gene Ther 15: $730-738,2008$
16. Spaeth EL, Dembinski JL, Sasser AK, Watson K, Klopp A, Hall B, Andreeff M and Marini F: Mesenchymal stem cell transition to tumor-associated fibroblasts contributes to fibrovascular network expansion and tumor progression. PLoS One 4: e4992, 2009.

17. Gunn WG, Conley A, Deininger L, Olson SD, Prockop DJ and Gregory CA: A crosstalk between myeloma cells and marrow stromal cells stimulates production of DKK1 and interleukin-6: A potential role in the development of lytic bone disease and tumor progression in multiple myeloma. Stem Cells 24: 986-991, 2006.

18. Kucerova L, Matuskova M, Hlubinova K, Altanerova V and Altaner C: Tumor cell behaviour modulation by mesenchymal stromal cells. Mol Cancer 9: 129, 2010.

19. Lu YR, Yuan Y, Wang XJ, Wei LL, Chen YN, Cong C, Li SF, Long D, Tan WD, Mao YQ, et al: The growth inhibitory effect of mesenchymal stem cells on tumor cells in vitro and in vivo. Cancer Biol Ther 7: 245-251, 2008.

20. Motaln H, Gruden K, Hren M, Schichor C, Primon M, Rotter A and Lah TT: Human mesenchymal stem cells exploit the immune response mediating chemokines to impact the phenotype of glioblastoma. Cell Transplant 21: 1529-1545, 2012.

21. Albarenque SM, Zwacka RM and Mohr A: Both human and mouse mesenchymal stem cells promote breast cancer metastasis. Stem Cell Res 7: 163-171, 2011.

22. Karnoub AE, Dash AB, Vo AP, Sullivan A, Brooks MW, Bell GW, Richardson AL, Polyak K, Tubo R and Weinberg RA: Mesenchymal stem cells within tumour stroma promote breast cancer metastasis. Nature 449: 557-563, 2007.

23. Polyak K and Weinberg RA: Transitions between epithelial and mesenchymal states: Scquisition of malignant and stem cell traits. Nat Rev Cancer 9: 265-273, 2009.

24. Soleimani M and Nadri S: A protocol for isolation and culture of mesenchymal stem cells from mouse bone marrow. Nat Protoc 4: 102-106, 2009.

25. Dominici M,Le Blanc K,Mueller I, Slaper-Cortenbach I, MariniF, Krause D,DeansR,Keating A,ProckopD and Horwitz E: Minimal criteria for defining multipotent mesenchymal stromal cells. the international society for cellular therapy position statement. Cytotherapy 8: 315-317, 2006.

26. Janni W, Rack B, Schindlbeck C, Strobl B, Rjosk D, Braun S, Sommer H, Pantel K, Gerber B and Friese K: The persistence of isolated tumor cells in bone marrow from patients with breast carcinoma predicts an increased risk for recurrence. Cancer 103: 884-891, 2005.

27. Janni W, Fehm T, Rack B, Muller V, Solomayer E, Stickeler E, Sommer H, Schindlbeck C, Juckstock J and Friese K: Clinical importance of the detection of isolated tumor cells in bone marrow and peripheral blood in patients with primary breast cancer. Geburtshilfe Und Frauenheilkunde 67: 653-660, 2007.

28. Hall C, Krishnamurthy S, Lodhi A, Mosalpuria K, Kuerer HM, Meric-Bernstam F, Bedrosian I, Hunt KK and Lucci A: Disseminated tumor cells in biologic subtypes of stage I-III breast cancer patients. Ann Surg Oncol 17: 3252-3258, 2010.

29. Beca F, Santos R, Vieira D, Zeferino L, Dufloth R and Schmitt F: Primary relapse site pattern in women with triple-negative breast cancer. Pathol Res Pract 210: 571-575, 2014.

30. Parker JS, Mullins M, Cheang MC, Leung S, Voduc D, Vickery T, Davies S, Fauron C, He X, Hu Z, et al: Supervised risk predictor of breast cancer based on intrinsic subtypes. J Clin Oncol 27: 1160-1167, 2009

31. Pantel K and Alix-Panabieres C: Bone marrow as a reservoir for disseminated tumor cells: A special source for liquid biopsy in cancer patients. Bonekey Rep 3: 584, 2014.

32. Braun S, Vogl FD, Naume B, Janni W, Osborne MP, Coombes RC, Schlimok G, Diel IJ, Gerber B, Gebauer G, et al: A pooled analysis of bone marrow micrometastasis in breast cancer. N Engl J Med 353: 793-802, 2005.

33. Hartkopf AD, Banys M, Meier-Stiegen F, Hahn M, Rohm C, Hoffmann J, Helms G, Taran FA, Wallwiener M, Walter C, et al: The HER 2 status of disseminated tumor cells in the bone marrow of early breast cancer patients is independent from primary tumor and predicts higher risk of relapse. Breast Cancer Res Treat 138: 509-517, 2013. 